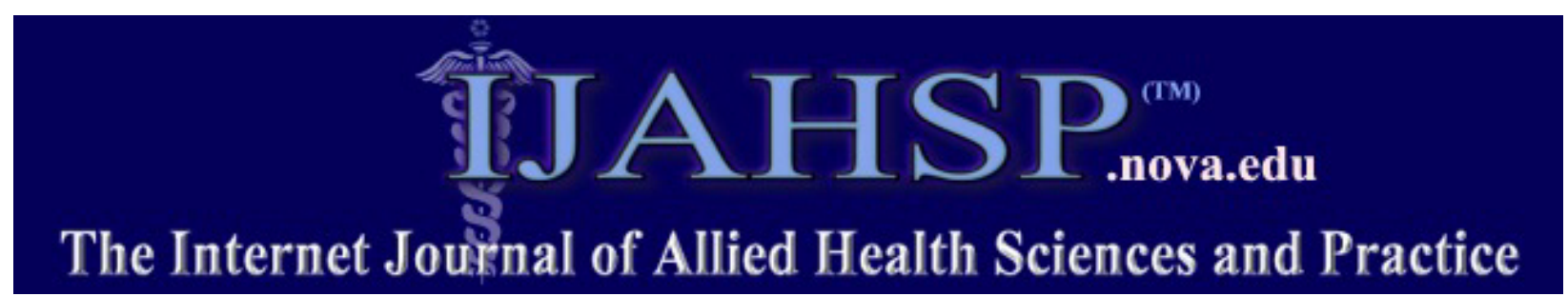

A Peer Reviewed Publication of the College of Health Care Sciences at Nova Southeastern University

Dedicated to allied health professional practice and education

http://ijahsp.nova.edu Vol. 10 No. 3 ISSN 1540-580X

\title{
Are Undergraduate Health Care Students 'Ready' for Interprofessional Learning? A Cross-Sectional Attitudinal Study
}

\author{
Brett Williams, PhD ${ }^{1}$ \\ Fiona McCook, PhD Candidate ${ }^{2}$ \\ Ted Brown, $\mathrm{PhD}^{3}$ \\ Claire Palmero, $\mathrm{PhD}^{4}$ \\ Lisa McKenna, $\mathrm{PhD}^{5}$ \\ Malcolm Boyle, $\mathrm{PhD}^{6}$ \\ Rebecca Scholes, $\mathrm{PhD}^{7}$ \\ Jill French, PhD Candidate ${ }^{8}$ \\ Louise McCall, $\mathrm{PhD}^{9}$
}

1. Director of Education, Department of Community Emergency Health and Paramedic Practice, Monash University,

Frankston, Victoria

2. Lecturer, Department of Rural and Indigenous Health, Monash University, Moe, Victoria

3. Associate Professor, Department of Occupational Therapy, Monash University, Frankston, Victoria

4. Lecturer, Department of Nutrition and Dietetics, Monash University, Notting Hill, Victoria

5. Associate Professor, School of Nursing and Midwifery, Monash University, Clayton, Victoria

6. Senior Lecturer, Department of Community Emergency Health and Paramedic Practice, Monash University, Frankston, Victoria

7. Senior Lecturer, Department of Physiotherapy, Monash University, Frankston, Victoria

8. Senior Lecturer, School of Nursing and Midwifery, Monash University, Berwick, Victoria

9. Associate Professor, Office Deputy Vice Chancellor, Monash University, Clayton, Victoria

Australia

CITATION: Williams B, McCook F, Brown T, Palmero C, McKenna L, Boyle M, Scholes R, French J, McCall L. Are Undergraduate Health Care Students 'Ready' for Interprofessional Learning? A Cross-Sectional Attitudinal Study. The Internet Journal of Allied Health Sciences and Practice. July 2012. Volume 10 Number 3.

\section{ABSTRACT}

Introduction: The need for interprofessional education (IPE) is driven by the recognition that one of the major focuses of the Australian health care system is the promotion of effective interprofessional learning and collaboration with the aim of providing optimal patient/client care. The objective of this study was to explore the attitudes towards readiness for interprofessional learning among a group of undergraduate health science students studying at Monash University. Method: A cross-sectional study of students across all undergraduate years from Nursing, Occupational Therapy, Emergency Health - Paramedic/Nursing, Nutrition and Dietetics, Emergency Health - Paramedic, Physiotherapy, and Midwifery was completed. Participants were asked to complete the 19-item paper-based Readiness for Interprofessional Learning Scale (RIPLS). Results: A total of 418 students participated in the study with most students from Nursing (25\%) followed by Paramedics (20\%). The majority of students were under 25 years of age (83\%) and female (80\%). Findings suggest that students support the notion of interprofessional collaboration in terms of teamwork, learning, and communication. The following items produced high mean scores: "patients 
would ultimately benefit if health care students worked together" $(M=4.33, S D+0.68)$, and "learning with other students will make me a more effective member of a health care team" $(M=4.38, S D+0.59)$. The item "shared learning will help me understand my own professional limitations" also produced significant findings $\bar{F}(6,411)=7.1, p<0.001$. Subscale scores ranged from 37.34 $(\mathrm{SD}+4.34)$ to $4.88(\mathrm{SD}+1.68)$. Conclusion: Overall, the study has revealed a generally positive attitude towards shared learning and the value of teamwork though the strength of optimism varies among professional groups of students. This study also adds to the emerging body of knowledge surrounding interprofessional learning and provides important data regarding students' perceptions and readiness for interprofessional learning from an Australian context.

\section{INTRODUCTION}

One of the major focuses of the Australian health care system and curricula reform issues within the higher education sector is the promotion of effective interprofessional collaboration with a view to providing optimal patient/client care. Interprofessional practice assumes that health professionals work collaboratively with each other, as well as with colleagues from other disciplines to provide patient care. ${ }^{1}$ The World Health Organization (WHO) reports that if professionals who work together in care teams are familiar with each others' roles and scopes of practice, this will ultimately improve the efficacy and effectiveness of care that patients and their families receive. ${ }^{2}$ Therefore, it is important that qualified health professionals and students studying to become qualified health practitioners have an adequate knowledge of one another's professions. ${ }^{3}$ While a number of different interprofessional education (IPE) definitions and terms exist, the definition of IPE adopted by the authors in this study is 'when two or more professions learn with, from, and about each other to improve collaboration and the quality of care' offers a range of opportunities for such interaction to occur. ${ }^{4,5}$

Interprofessional education and interprofessional practice is about changing the very culture of the healthcare system by breaking down the fixed professional silos which exist between different health care professions in order to promote symbiotic patient care. In recent times, the WHO stated that after nearly 50 years of investigation, it was argued that there was sufficient evidence that the new empathises on collaborative practice and IPE would strengthen healthcare service delivery systems and improve health outcomes around the world. ${ }^{2}$ Guiding this approach is a number of theoretical perspectives, all of which have evolved rapidly. ${ }^{6}$ Barr and colleagues argue that a number of theoretical models from a number of different fields have influenced the direction and evidence-base of IPE. ${ }^{6}$ Some of these fields include theories from education, psychology, management, and sociology. $6-8$ Examples include theories relating to adult learning, communities of practice, contact theory, and social defiance theory all of which provide an important theoretical base for IPE and future interprofessional practice. ${ }^{9-12}$

Participation in IPE initiatives can increase understanding among professional cultures of each other's customs, practices, and language as well as promote interprofessional collaboration and enhance professional practice. ${ }^{6}$ While this statement appears to be more applicable to the workplace, IPE is also considered increasingly important to implement at pre-registration level. ${ }^{13} \mathrm{Hind}$ et al. argued that the undergraduate level of students' education is the optimum time for interprofessional learning as it fosters positive attitudes to collaboration early in a student's professional life and can assist in pre-empting negative stereotypes of other professions. ${ }^{21}$ Curran and colleagues concur with this position, adding that to ensure success, IPE initiatives need to be welldesigned, delivered, integrated, and underpinned based on sound pedagogy. ${ }^{14}$ Moreover, as noted by the WHO, one of the major challenges and gaps in interprofessional learning and collaboration literature is the translation of attitudes and perceptions into behavioural change; change that leads to improved healthcare outcomes. In other words, the attitudes and awareness of undergraduate students about IPE may lead to informed behavioural changes in professional practice. Consequently, effective university-level IPE programs should incorporate strategies such as interactive and problem-based authentic learning environments that promote group work and collaboration, reflection and mentorship, while also reflecting the changing nature of healthcare provision. 15,16 Using these strategies and others in learning activities enable students to "investigate their professional roles and determine the boundaries between them."17,18 However, as with all learning activities, objectives and rationale for what is being undertaken and how the resultant learning will apply to future practice must be made explicit to the participants since failure to do so is to risk less than optimal learning outcomes.

While authors such as Cooper et al. support early career IPE, there are others who make the case that IPE interventions are better conducted late in the undergraduate curriculum either when health care students have gained experience, insight and a sense of their own professional identity or when the student may have a much clearer idea of their future responsibilities as a practicing clinician and how IPE may help.13,19,20 Taking part in IPE activities may be better placed in an undergraduate curriculum after students have had the opportunity to complete some practice education where they have gained experience of working in real life clinical/professional settings. This would provide students with a point of reference to contextualise and identify IPE activities. 
This study explored the attitudes towards readiness for interprofessional learning among a group of undergraduate students studying enrolled in seven health science-related courses at Monash University using the Readiness for Interprofessional Learning Scale (RIPLS). ${ }^{16}$

\section{METHOD \\ Design}

A cross-sectional study using a paper-based version of the RIPLS and a brief demographic questionnaire were administered to a cohort of students enrolled in health-related courses.

\section{Participants}

Students were undergraduates enrolled in one of seven health-related courses: Nursing, Occupational Therapy, Emergency Health - Paramedic/Nursing, Nutrition and Dietetics, Emergency Health - Paramedic, Physiotherapy, and Midwifery at Monash University's Faculty of Medicine, Nursing, and Health Science. Any undergraduate student enrolled in one of these seven courses was eligible to participate in the study. All eligible students had previously enrolled in the faculty's interprofessional unit of study during first year studies, and had all engaged in some form of interprofessional collaborative practice during clinical placements. For example, physiotherapy and occupational therapy students would have collaborated with other health professionals such as social workers, speech therapists, nurses, and rehabilitation physicians while paramedic students would have had interactions with nurses and physicians during practice education placements. Nutrition and dietetics students would have had interprofessional contact with nurses, physicians, social workers, and speech therapists.

\section{Instrumentation}

The Readiness for Interprofessional Learning Scale (RIPLS) is a measure of students' attitudes towards engaging in interprofessional learning (IPL). It is a 19-item scale that uses a 5-point Likert-scale (1=strongly disagree and 5=strongly agree) with three subscales: team work and collaboration, professional identity, and roles and responsibilities (see Table 1). The original authors did not suggest reversing any items, despite several items having negative item stems. In the original development of the scale, the RIPLS was found to be valid and reliable ${ }^{16}$. Subsequent studies using similar healthcare cohorts (medicine, nursing, physiotherapy, nutrition and dietetics, and pharmacy) have also found the RIPLS to demonstrate acceptable levels of validity and reliability. ${ }^{21,22}$ McFadyen et al. conducted a test-retest reliability study on a revised version of the RIPLS and found that overall the scale exhibited satisfactory reliability, but identified areas for improvement, mainly in the roles and responsibilities subscale. ${ }^{23}$

\begin{tabular}{|c|c|c|c|c|c|c|}
\hline \multicolumn{7}{|c|}{ Table 1. Original RIPLS 16} \\
\hline & & $\begin{array}{l}\text { Strongly } \\
\text { agree }\end{array}$ & Agree & Undecided & Disagree & $\begin{array}{l}\text { Strongly } \\
\text { disagree }\end{array}$ \\
\hline 1. & $\begin{array}{l}\text { Learning with other students will make me } \\
\text { a more effective member of a health care } \\
\text { team }\end{array}$ & 5 & 4 & 3 & 2 & 1 \\
\hline 2. & $\begin{array}{l}\text { Patients would ultimately benefit if health } \\
\text { care students worked together }\end{array}$ & 5 & 4 & 3 & 2 & 1 \\
\hline 3. & $\begin{array}{l}\text { Shared learning with other health care } \\
\text { students will increase my ability to } \\
\text { understand clinical problems }\end{array}$ & 5 & 4 & 3 & 2 & 1 \\
\hline 4. & $\begin{array}{l}\text { Communication skills should be learned } \\
\text { with other health care students }\end{array}$ & 5 & 4 & 3 & 2 & 1 \\
\hline 5. & $\begin{array}{l}\text { Team-working skills are vital for all health } \\
\text { care students to learn }\end{array}$ & 5 & 4 & 3 & 2 & 1 \\
\hline 6. & $\begin{array}{l}\text { Shared learning will help me to understand } \\
\text { my own professional limitations }\end{array}$ & 5 & 4 & 3 & 2 & 1 \\
\hline 7. & $\begin{array}{l}\text { Learning between health care students } \\
\text { before qualification would improve working } \\
\text { relationships after qualification }\end{array}$ & 5 & 4 & 3 & 2 & 1 \\
\hline 8. & $\begin{array}{l}\text { Shared learning will help me think } \\
\text { positively about other health care } \\
\text { professionals }\end{array}$ & 5 & 4 & 3 & 2 & 1 \\
\hline 9. & $\begin{array}{l}\text { For small-group learning to work, students } \\
\text { need to respect and trust each other }\end{array}$ & 5 & 4 & 3 & 2 & 1 \\
\hline
\end{tabular}




\begin{tabular}{|c|l|c|c|c|c|c|}
\hline & \multicolumn{1}{|c|}{$\begin{array}{c}\text { Strongly } \\
\text { agree }\end{array}$} & Agree & Undecided & Disagree & $\begin{array}{c}\text { Strongly } \\
\text { disagree }\end{array}$ \\
\hline 10. & $\begin{array}{l}\text { I don't want to waste time learning with } \\
\text { other health care students }\end{array}$ & 5 & 4 & 3 & 2 & 1 \\
\hline 11. & $\begin{array}{l}\text { It is not necessary for undergraduate } \\
\text { health care students to learn together }\end{array}$ & 5 & 4 & 3 & 2 & 1 \\
\hline 12. & $\begin{array}{l}\text { Clinical problem solving can only be learnt } \\
\text { effectively with students from my own } \\
\text { school }\end{array}$ & 5 & 4 & 3 & 2 & 1 \\
\hline 13. & $\begin{array}{l}\text { Shared learning with other health care } \\
\text { professionals will help me to communicate } \\
\text { better with patients and other } \\
\text { professionals }\end{array}$ & 5 & 4 & 3 & 2 & 1 \\
\hline 14. & $\begin{array}{l}\text { I would welcome the opportunity to work } \\
\text { on small group projects with other health } \\
\text { care students }\end{array}$ & 5 & 4 & 3 & 2 & 1 \\
\hline 15. & $\begin{array}{l}\text { The function of nurses and allied health } \\
\text { care workers is mainly to provide support } \\
\text { for doctors }\end{array}$ & 5 & 4 & 3 & 2 & 1 \\
\hline 16. & $\begin{array}{l}\text { Shared learning will help me clarify the } \\
\text { nature of patients' or clients' problems }\end{array}$ & 5 & 4 & 3 & 2 & 1 \\
\hline 17. & $\begin{array}{l}\text { Shared learning before qualification will } \\
\text { help me become a better team worker }\end{array}$ & 5 & 4 & 3 & 2 & 1 \\
\hline 18. & $\begin{array}{l}\text { I am not sure what my professional role } \\
\text { will be }\end{array}$ & 5 & 4 & 3 & 2 & 1 \\
\hline 19. & $\begin{array}{l}\text { I have to acquire much more knowledge } \\
\text { and skill than other students in my own } \\
\text { faculty }\end{array}$ & 5 & 4 & 3 & 2 & 1 \\
\hline
\end{tabular}

\section{PROCEDURES}

Participants received an explanatory statement outlining the purpose of the study beforehand and were informed that participation was voluntary and anonymous. Each participant completed the self-reported RIPLS questionnaire and a brief set of demographic questions. The questionnaire was completed at the end of a lecture for each respective group of health science students and took approximately 10 minutes to complete. A non-teaching member of staff facilitated the process and collected the questionnaires. Consent was implied by completion and submission of the questionnaires.

\section{DATA ANALYSIS}

The Statistical Package for Social Sciences (SPSS; Version 17.0) was used for data storage, tabulation, and the generation of descriptive statistics. Means and standard deviations (SD) were used to report the demographic data with t-tests and one-way analysis of variance (ANOVA) tests used to analyze the differences between courses, gender, and year of course. Parametric tests were used despite the data being ordinal level. Although methodologists hotly debate the use of parametric testing with ordinal level data, a growing body of literature is more pragmatic and supportive of its use..$^{24-27}$ The results were considered statistically significant if the $p$ value was $<0.05$.

\section{ETHICS}

Ethics approval was obtained from the Monash University Standing Committee on Ethics in Research Involving Humans (SCERH).

\section{RESULTS \\ Demographics}

A total of 418 students participated in this study, which represented a $30.2 \%$ response rate. The majority of participates were female $(80.4 \%)$ and the majority were young adults $(<21$ years $=25.1 \% ; 21-25$ years $=58.1 \%)$. Each year level was adequately represented for statistical analysis $\left(2^{\text {nd }}\right.$ year $=47.4 \% ; 3^{\text {rd }}$ year $=29.9 \% ; 4^{\text {th }}$ year $\left.=21.8 \%\right)$. The distribution of other demographic data is shown in Table 2. The internal consistency for the RIPLS as measured by Cronbach's Coefficient Alpha was good with a reported $(0.84)$ for the total scale. ${ }^{28}$ 
Table 2. Demographics

\begin{tabular}{|l|l|l|}
\hline Health Professional Course & Number & Percentage \\
\hline Emergency Health (Paramedic) & 83 & 19.9 \\
\hline Nursing & 108 & 25.8 \\
\hline Midwifery & 16 & 3.8 \\
\hline Nursing/Emergency Health (Paramedic) & 40 & 9.6 \\
\hline Occupational Therapy & 42 & 10.0 \\
\hline Physiotherapy & 55 & 13.2 \\
\hline Nutrition \& Dietetics & 74 & 17.7 \\
\hline Total & 418 & 100 \\
\hline Year & Number & Percentage \\
\hline First year & 1 & 0.2 \\
\hline Second year & 198 & 47.4 \\
\hline Third year & 125 & 29.9 \\
\hline Fourth year & 91 & 21.8 \\
\hline Fifth year & 3 & 0.7 \\
\hline Total & 418 & 100 \\
\hline Age & Number & Percentage \\
\hline$<21$ years & 105 & 25.1 \\
\hline $21-25$ years & 243 & 58.1 \\
\hline $26-30$ years & 29 & 6.9 \\
\hline $31-35$ years & 13 & 3.1 \\
\hline $36-40$ years & 17 & 4.1 \\
\hline $41-45$ years & 6 & 1.4 \\
\hline$>45$ years & 5 & 1.2 \\
\hline Total & 418 & 100 \\
\hline Gender & Number & Percentage \\
\hline Female & 336 & 80.4 \\
\hline Male & 82 & 19.6 \\
\hline & & \\
\hline & 13 & \\
\hline & 13 & \\
\hline
\end{tabular}

\section{Construct Validity of the RIPLS}

With previous literature questioning the factor structure of the original 3-factor 19-item RIPLS, a factor analysis with oblimin rotation was undertaken to examine the construct validity of the RIPLS. ${ }^{23,29}$ Results following the factor analysis (item correlations $>0.30$ ) suggested multidimensionality with 18 -items loading onto four factors accounting for $41.6 \%$ of the explained variance (see Table 3).

There were seven items that loaded on subscale 1, teamwork and collaboration, with item loadings ranging from 0.34-0.77 and explaining $31.3 \%$ of the variance. The top item within the factor was "learning with other students will make me a more effective member of a health care team." Subscale 1 included other items such as "communication skills should be learned with other health care students," and "patients would ultimately benefit if health care students worked together." There were four items that loaded on subscale 2, roles and responsibilities with item loadings ranging from $0.30-0.43$ and explaining $4.80 \%$ of the variance. The top item within the actor was "I have to acquire much more knowledge and skill than other students in my own faculty." Subscale 2 included other items such as "clinical problem solving can only be learnt effectively with students from my own school." There were six items that loaded on subscale 3, professional identity, with item loadings ranging from 0.81-0.38 and explaining $3.04 \%$ of the variance. The top item within the factor was "shared learning will help me clarify the nature of patients' or 
clients' problems." Subscale 3 included other items such as "the function of nurses and allied health is mainly to provide support for doctors" and "I would welcome the opportunity to work on small group projects with other health care students."

Only one item loaded on subscale 4 "shared learning will help me think positively about other health care professionals" and thus is not viable for analysis. ${ }^{21}$ The item "for small-group learning to work, students need to respect and trust each other" did not load on any factor.

Table 3. Pattern Matrix - Factor Analysis (Oblimin Rotation) ( $n=418)$

\begin{tabular}{|c|c|c|c|c|}
\hline \multicolumn{5}{|c|}{ Pattern Matrix } \\
\hline & \multicolumn{4}{|c|}{ Component } \\
\hline & $\begin{array}{c}1 \\
a 0.77\end{array}$ & $\begin{array}{c}2 \\
\text { a } 0.50\end{array}$ & $\begin{array}{c}3 \\
a 0.53\end{array}$ & 4 \\
\hline $\begin{array}{l}\text { Learning with other students will make me a more effective } \\
\text { member of a health care team (item 1) }\end{array}$ & .776 & & & \\
\hline $\begin{array}{l}\text { Patients would ultimately benefit if health care students } \\
\text { worked together (item 2) }\end{array}$ & .662 & & & \\
\hline $\begin{array}{l}\text { Shared learning with other health care students will increase } \\
\text { my ability to understand clinical problems (item } 3 \text { ) }\end{array}$ & .656 & & & \\
\hline $\begin{array}{l}\text { Communication skills should be learned with other health } \\
\text { care students (item 5) }\end{array}$ & .590 & & & \\
\hline $\begin{array}{l}\text { Learning between health care students before qualification } \\
\text { would improve working relationships after qualification (item } \\
\text { 4) }\end{array}$ & .410 & & & \\
\hline $\begin{array}{l}\text { Team-working skills are vital for all health care students to } \\
\text { learn (item 8) }\end{array}$ & .373 & & & \\
\hline $\begin{array}{l}\text { Shared learning will help me to understand my own } \\
\text { professional limitations (item 9) }\end{array}$ & .341 & & & \\
\hline $\begin{array}{l}\text { I have to acquire much more knowledge and skill than other } \\
\text { students in my own faculty (item 19) }\end{array}$ & & .436 & & \\
\hline I am not sure what my professional role will be (item 18) & & .432 & & \\
\hline $\begin{array}{l}\text { I don't want to waste time learning with other health care } \\
\text { students (item 10) }\end{array}$ & & .402 & & \\
\hline $\begin{array}{l}\text { Clinical problem solving can only be learnt effectively with } \\
\text { students from my own school (item 12) }\end{array}$ & & .302 & & \\
\hline $\begin{array}{l}\text { Shared learning will help me clarify the nature of patients' or } \\
\text { clients' problems (item 15) }\end{array}$ & & & .816 & \\
\hline $\begin{array}{l}\text { Shared learning before qualification will help me become a } \\
\text { better team worker (item 16) }\end{array}$ & & & .811 & \\
\hline $\begin{array}{l}\text { The function of nurses and allied health is mainly to provide } \\
\text { support for doctors (item 17) }\end{array}$ & & & .645 & \\
\hline $\begin{array}{l}\text { I would welcome the opportunity to work on small group } \\
\text { projects with other health care students (item 14) }\end{array}$ & & & .406 & \\
\hline $\begin{array}{l}\text { It is not necessary for undergraduate health care students to } \\
\text { learn together (item 11) }\end{array}$ & & & .399 & \\
\hline $\begin{array}{l}\text { Shared learning with other health care professionals will help } \\
\text { me to communicate better with patients and other } \\
\text { professionals (item 13) }\end{array}$ & & & .389 & \\
\hline $\begin{array}{l}\text { Shared learning will help me think positively about other } \\
\text { health care professionals (item } 6 \text { ) }\end{array}$ & & & & .400 \\
\hline
\end{tabular}


The raw mean scores for the nineteen RIPLS item scores are reported in Table 4. The mean scores for each subscale were: subscale $1(M=37.34, S D+4.34)$, subscale $2(M=21.69, S D+2.30)$, subscale $3(M=11.90, S D+2.02)$, and subscale $4(M=4.88$, $\mathrm{SD}+1.68)$. As suggested by McFadyen et al., we also reversed scored items 10,11 , and 12 despite not being previously suggested by the original authors. ${ }^{29}$

Table 4. Combined Responses to Readiness for Interprofessional Learning Scale (RIPLS) ( $\mathrm{n}=418)$

\begin{tabular}{|l|l|l|}
\hline Item & M & SD \\
\hline Learning with other students will make me a more effective member of a health care team & 4.38 & 0.59 \\
\hline Patients would ultimately benefit if health care students worked together & 4.33 & 0.68 \\
\hline Shared learning with other health care students will increase my ability to understand clinical problems & 4.24 & 0.69 \\
\hline Communication skills should be learned with other health care students & 4.20 & 0.78 \\
\hline Team-working skills are vital for all health care students to learn & 4.62 & 0.55 \\
\hline Shared learning will help me to understand my own professional limitations & 4.10 & 0.71 \\
\hline $\begin{array}{l}\text { Learning between health care students before qualification would improve working relationships after } \\
\text { qualification }\end{array}$ & 4.26 & 0.69 \\
\hline Shared learning will help me think positively about other health care professionals & & \\
\hline For small-group learning to work, students need to respect and trust each other & 4.11 & 0.74 \\
\hline I don't want to waste time learning with other health care students & 4.48 & 0.63 \\
\hline It is not necessary for undergraduate health care students to learn together & 1.99 & 0.81 \\
\hline Clinical problem solving can only be learnt effectively with students from my own school & 2.03 & 0.82 \\
\hline $\begin{array}{l}\text { Shared learning with other health care professionals will help me to communicate better with patients and } \\
\text { other professionals }\end{array}$ & 2.08 & 0.17 \\
\hline I would welcome the opportunity to work on small group projects with other health care students & 0.70 \\
\hline Shared learning will help me clarify the nature of patients' or clients' problems & 3.88 & 0.87 \\
\hline Shared learning before qualification will help me become a better team worker & 4.05 & 0.73 \\
\hline The function of nurses and allied health care workers is mainly to provide support for doctors & 4.21 & 0.66 \\
\hline I am not sure what my professional role will be & 3.99 & 0.80 \\
\hline I have to acquire much more knowledge and skill than other students in my own faculty & 2.23 & 1.07 \\
\hline
\end{tabular}

"Teamworking skills are vital for all healthcare students to learn" was the item rated highest overall by students ( $M=4.62$, $\mathrm{SD} \pm 0.550)$. Post hoc comparisons of this finding revealed there was a statistically significant difference, $p=0.007$, between Nutrition and Dietetics students $(M=4.82, S D+0.41)$, who were the profession most in agreement, and those from Paramedics $(\mathrm{M}=4.51, \mathrm{SD}+0.54)$, who while still holding favourable attitudes towards teamworking, were below the overall mean of 4.62 . Continuing with the same theme, the item "patients would ultimately benefit if healthcare students worked together" was also rated highly by students $(M=4.33, S D+0.68)$ and again this result was significant across courses, $p<0.001$. Nutrition and Dietetics agreed most strongly with the item $(M=4.55, S D+0.68)$ whereas Physiotherapy $(M=3.85, S D+0.82)$ was the group that agreed least strongly. The other student groups were clustered more tightly within a 0.10 range: Nursing/Paramedics ( $M=4.43$, $S D=0.59)$, Paramedics $(M=4.39, S D+0.53)$, Nursing $(M=4.35, S D+0.64)$, and Occupational Therapy $(M=4.33, S D \pm 0.71)$.

Results also indicated that students had positive attitudes towards shared learning and were aware of the benefits that this collaboration could provide. Improving teamwork skills rated highly, with students reporting that "learning with other students will make me a more effective member of a health care team" (M=4.38, SD+0.59) and "shared learning before qualification will help me become a better team worker" $(\mathrm{M}=4.21, \mathrm{SD}+0.66)$.

Post-hoc comparisons on these two items revealed significant differences, $p<0.001$, among student groups. In both items, students in Nutrition and Dietetics reported the highest rate of agreement $(M=4.61, S D+0.54$ and $M=4.58, S D+0.57)$ whereas the lowest level of agreement with the same two items was among Physiotherapy students $(M=3.95, S D+0.62)$.

The perceived benefits of collaborative learning in enhancing professional knowledge and values rated only slightly less highly, "shared learning with other health care students will increase my ability to understand clinical problems" $(M=4.24, S D+0.69)$ and "shared learning will help me to understand my own professional limitations" (M=4.10, SD+0.71). Interestingly, the second item, concerning professional limitations, produced significant findings, $p<0.001$, across healthcare professions. Nutrition and Dietetics students $\left(M=4.47, S_{-}+6.64\right)$ reported the strongest agreement whereas Physiotherapy students concurred the least $(\mathrm{M}=3.80, \mathrm{SD}+0.59)$. The mean ratings of the remaining four professions (Nursing, Nursing/Paramedics, Paramedics, Occupational Therapy) fell within the range $M=4.16-M=3.93$. 
Shared learning was considered to also have a positive impact on working relationships with students rating strongly, "learning between healthcare students before qualification would improve working relationships after qualification" (M=4.26, $S D+0.691)$ and "shared learning with other health care professionals will help me to communicate better with patients and other professionals" (M=4.17, SD+0.707). Post-hoc comparisons on this second item again showed Nutrition and Dietetics ( $M=4.72$, $S D+0.48)$ as significantly different, $p<0.001$, from other health professions, Nursing $(M=4.18, S D+0.80)$, Paramedics $(M=4.05$, $\mathrm{SD}+0.67)$, Occupational Therapy $(\mathrm{M}=4.05, \mathrm{SD}+0.62)$, and Physiotherapy $(\mathrm{M}=3.85, \mathrm{SD}+0.59)$.

One finding which stands slightly apart from this group of shared-learning benefits because it pertains to the pre-requisite qualities needed for shared learning to be successful, rather than being a perceived result of collaborative learning, is the high overall rating given to "for small group learning to work, students need to respect and trust each other" $(M=4.48, S D+0.631)$. Again, the results are significant across professions, $p<0.001$, with Nutrition and Dietetics $(M=4.72, S D+0.48)$ recording the highest agreement with the statement, whereas Nursing $(M=4.43, S D+0.68)$ and Paramedics $(M=4.35, S D+0.70)$ while still high, fall below the $M=4.48$ mean for the cohort.

\section{DISCUSSION}

The overall results of this study provide qualified support for the inclusion of interprofessional learning and teamwork activities in undergraduate health curricula while at the same time raising questions about the extent to which prior learning experiences, previous practice education opportunities, and emerging professional identity influence students' attitudes towards such activities. Most students were clearly receptive to both working on an interprofessional team and to participating in collaborative learning activities with other health care students and were aware of the benefits of both. This finding corresponds with similar studies conducted among health care students. ${ }^{21,30,31}$ However the underlying latent constructs in the original RIPLS were not replicated in this study, suggesting that further validation studies need to be undertaken on the measurement properties of the RIPLS.

All three groups of investigators found that students reported a greater understanding of teamwork and collaboration and an increased knowledge of the different professional roles knowledge and skills of other health professionals after interprofessional learning interventions. However, the most interesting aspect of the current study was the consistency with which one health profession, dieticians, gave four key survey items the highest rating, and similarly and contrastingly, the consistency with which another health profession, physiotherapists, gave the same four items the lowest rating.

One result that is significant is the consistent highest mean ratings given to both the value of team work and the support of collaborative learning by dietetics students ("patients would ultimately benefit if healthcare students worked together," "shared learning before qualification will help me become a better team worker," "shared learning with other health care students will increase my ability to understand clinical problems," "shared learning with other health care professionals will help me to communicate better with patients and other professionals"). This group's more positive attitude may reflect the training of dietetics students who undertake their program within a clinical environment where training is received from a multidisciplinary team. This suggests that the dietetics students' proximity to other health professionals may engender positive attitudes towards cooperation and adds weight to the argument that interprofessional education activities are best delivered during the preregistration phase of professional experience before a trainee has become fully socialised into the culture of their discipline. ${ }^{13}$

It may be possible that the dieticians' high level of concurrence is indicative of a combination of situational factors rather than just proximity to other professionals. ${ }^{31}$ Some propose that macro factors within the host organisation, that is, the social, cultural, professional and educational systems, and meso-level factors, which include a supportive organisational philosophy, administrative support and communication, should be aligned within the dieticians' learning environment, if they are to impact on attitudes and future practice. It was beyond the scope of this study to establish whether in fact the dieticians' clinical training environment did contribute to collaborative attitudes and whether this will lead to collaborative practice, but it would appear that to ensure pre-registration education builds on these positive attitudes towards interprofessional collaboration to produce competent interprofessional health practitioners and ultimately, cost-effective and improved patient care, then further research in this area is urgently needed.

In contrast to the high ratings given to interprofessional learning and teamwork items by dieticians, physiotherapists gave the same four items the lowest rating among the professional groups ( $M=3.85,3.95,3.80,3.85)$. Although overall, physiotherapists' attitudes were favourable, there was a consistent $>0.5$ mean difference (lower) between their level of agreement and that of the dieticians in all four items. Without any qualitative data to contextualise these findings, a causal relationship for the physiotherapists' lower ratings is difficult to establish. However, as suggested by Hind et al. in their study of healthcare students, this less favourable rating of collaborative learning and the value of teamwork may be due to the quality and quantity of 
interactions that physiotherapy students have had with other professional groups. ${ }^{21}$ Further investigation of these factors may identify a point at which optimal conditions, for example, the types and number of learning activities participated in and the composition of the interprofessional learning groups, are present and learning is most likely to achieve the best outcomes. Of course, these less constructive interactions could also signify either unaligned macro and meso-level factors or a complete absence of one or some of the factors.

Another possible influence on the physiotherapists' attitudes could be the preconceptions that they bring to their training. A study by Glen and Reeves, which found that some student professional groups already held stereotypical views of one another, questioned whether students would be motivated to learn in such circumstances. ${ }^{32}$ In the present situation, where students held generally positive views towards collaborative learning and teamwork, this reservation would appear to be unfounded. However, it would be useful to conduct a similar survey of attitudes at a later stage in the students' training to assess whether these attitudes were maintained once students became more socialised into their profession.

One other potential explanation for the physiotherapists' results which could prove difficult to substantiate because of ethical concerns is the possibility of resistance to interprofessional initiatives where students do not consider that collaborative sessions help them develop the capabilities specific to their profession. ${ }^{33}$ This resistance may originate among faculty members where defensiveness, a lack of respect, or just a simple lack of knowledge of other professions' roles and responsibilities communicates itself to the students and becomes part of the students' emerging professional identity. ${ }^{34}$

Moving from the team level items discussed in the previous paragraphs to the interpersonal level, trust was acknowledged as a significant factor in the efficacy of teamwork. This finding concurs with that of Kennard who, in a study of qualified health professionals, found that trust was considered a central notion of teamwork, and that in situations where trust was not evident, interpersonal relationships were dysfunctional. ${ }^{35}$

A potential limitation to the study is the generalisability of the results. This sample of health science students were drawn from one major Australian university and consequently may not be representative of student groups from other Australian universities. Future studies might also consider using a mixed methodological approach to gain a better insight surrounding students' perceptions and attitudes. Using a qualitative design may also unearth other factors that may impact students' attitudes and perceptions to interprofessional education (e.g., hidden curriculum, professional socialisation, clinical placement education). A further limitation of the study was the variable exposure of interprofessional collaborative practice by students during clinical placements thereby potentially confounding the results. While it is not possible for every student to experience the same situations during placements, future studies might consider some form of experimental design to control for these confounders. Another acknowledged limitation of this study was the use of convenience sampling. This method, while an easy way to recruit participants, is less likely to draw on a representative sample of students. Those students who do volunteer to respond may bias the results. However, for ethical reasons, it is not possible to make it a requirement that participants such as students complete a questionnaire unless they volunteer to do so.

\section{CONCLUSION}

Overall, the study has revealed a generally positive attitude toward shared learning and the value of teamwork though the strength of optimism varies among professions. An investigation of the possible reasons for these disparities among the student health profession groups offers potential for future investigation. However, it should also be remembered that there can often be a misalignment between attitudes, beliefs, and behaviour so that while the results are generally encouraging, they are not necessarily predictive of current or future practice. Thus, it would be instructive to determine, perhaps through observational studies, whether these attitudes toward teamwork and collaboration are indicative of more than just surface acceptance and do in fact translate into practice.

\section{COMPETING INTERESTS}

No competing interests.

\section{ACKNOWLEDGEMENTS}

We would like to acknowledge the funding provided by the State Government of Victoria, Department of Human Services (Service and Workforce Program). We are also grateful to the students who volunteered their time and input to participate in the study. 


\section{REFERENCES}

1. McCallin A. Interprofessional practice: Learning how to collaborate. Contemporary Nurse. 2005;20(1):28-37.

2. World Health Organization. Framework for Action on Interprofessional Education\& Collaborative Practice. Geneva: World Health Organization; 2010.

3. Ponzer S, Hylin U, Kusoffsky A, Lauffs M, Lonka K,Mattiasson AC, Nordstrom G. Interprofessional training in the context of clinical practice: goals and students' perceptions on clinical education wards. Medical Education. 2004;38(7):727-36. DOI: 10.1111/j.1365-2929.2004.01848.x

4. Stone J. Interprofessional Collaborative Practice - Definitions and Terminology: Attempting to speak the same language. Canberra, ACT: ACT Health; 2009.

5. Centre for the Advancement of Interprofessional Education. Interprofessional education: A definition. London: CAIPE; 1997.

6. Barr H, Koppel I, Reeves S, Hammick M, Freeth D. Effective Interprofessional Education: Argument, Assumption \& Evidence. Oxford: Blackwell Publishing Ltd; 2005.

7. Hammick M. Interprofessional education: concept, theory and application. Journal of Interprofessional Care. 1998;12(3):323-32.

8. Walsh C, Gordon F, Marshall M, Wilson F, Hunt T. Interprofessional capability: A developing framework for interprofessional education. Nurse Education in Practice. 2005;5(4):230-7.

9. Knowles MS. Self-directed Learning: a Guide for Learners and Teachers. Chicago: Follett; 1975.

10. Lave J, Wenger E. Situated Learning: Legitimate Peripheral Participation. Cambridge: Cambridge University Press; 1991.

11. Allport GW. The Nature of Prejudice. 25th ed. Cambridge: Perseus Books Publishing 1979.

12. Menzies IE. The Functioning of Social Systems as a Defence Against Anxiety. London: Tavistock Institute of Human Relations; 1970.

13. Cooper H, Spencer-Dawe E, Mclean E. Beginning the process of teamwork: Design, implementation and evaluation of an inter-professional education intervention for first year undergraduate students. Journal of Interprofessional Care. 2005;19(5):492-508.

14. Curran VR, Sharpe D, Flynn K, Button P. A longitudinal study of the effect of an interprofessional education curriculum on student satisfaction and attitudes toward interprofessional teamwork and education. Journal of Interprofessional Care. 2010;24(1):41-52.

15. Humphris D, Hean S. Educating the future workforce: building the evidence about interprofessional learning. Journal of Health Services Research and Policy. 2004;9(1):24-7.

16. Parsell G, Bligh J. The Development of a questionnaire to assess the readiness of health care students for interprofessional learning (RIPLS). Medical Education. 1999;22:95-100.

17. Cooke S, Chew-Graham C, Boggis C, Wakefield A. I never realised that doctors were into feelings too: changing student perceptions through interprofessional education. Learning in Health and Social Care. 2003;2(3):137-46.

18. Faresjo T. Interprofessional education- to break boundaries and build bridges. Rural and Remote Health. 2006;6:602.

19. Pirrie A, Hamilton S, Wilson V. Multidisciplinary education: some issues and concerns. Educational Research. 1999;41(3):301-14.

20. Swanwick T. Understanding medical education: Evidence, theory and practice Oxford: Wiley-Blackwell; 2010.

21. Hind M, Norman I, Cooper S, Gill E, Hilton R, Judd P, et al. Interprofessional perceptions of health care students. Journal of Interprofessional Care. 2003;17(1):21-34.

22. Horsburgh M, Lamdin R, Williamson E. Multiprofessional learning: the attitudes of medical, nursing and pharmacy students to shared learning. Medical Education. 2001;35(9):876-83.

23. McFadyen AK, Webster VS, Maclaren WM. The test-retest reliability of a revised version of the Readiness for Interprofessional Learning Scale (RIPLS). Journal of Interprofessional Care. 2006;20(6):633-9.

24. Norman G. Likert scales, levels of measurement and the "laws" of statistics. Advances in Health Science Education. 2010;15(5):625-32.

25. Wright DB. Football standings and measurement levels. The Statistician: Journal of the Royal Statistical Society Series D. 1997;46(1):105-10.

26. Wright DB. Making friends with your data: Improving how statistics are conducted and reported. British Journal of Educational Psychology. 2003;73(1):123-36.

27. Lord FM. On the statistical treatment of football numbers. American Psychologist. 1953;8(12):750-1.

28. Hair J, Anderson RE, Tatham RL, Black WC. Multivariate data analysis. 4th ed. New Jersey: Prentice-Hall Inc; 1995.

29. McFadyen AK, Webster VS, Strachan K, Figgens E, Brown H, McKenchnie J. The Readiness for Interprofessional Learning Scale: A possible more stable sub-scale model for the original version of RIPLS. Journal of Interprofessional Care. 2005;19(6):595-603.

30. Bradley P, Cooper S, Duncan F. A mixed-methods study of interprofessional learning of resuscitation skills. Medical Education. 2009;43(9):912-22. 
31. D'Amour D, Oandasan I. Interprofessionality as the field of interprofessional practice and interprofessional education: An emerging concept. Journal of Interprofessional Care. 2005;19(s1):8-20.

32. Glen $\mathrm{S}$, Reeves $\mathrm{S}$. Developing interprofessional education in the pre-registration curricula: mission impossible? Nurse Education in Practice. 2004;4(1):45-52. [PMID 19038136]

33. Howell D. Occupational therapy students in the process of interprofessional collaborative learning: A grounded theory study. Journal of Interprofessional Care. 2009;23(1):67-80.

34. Steinert Y. Learning together to teach together: Interprofessional education and faculty development. Journal of Interprofessional Care. 2005;19(s1):60-75.

35. Kennard J. Illuminating the relationship between shared learning and the workplace. Medical Teacher. 2002;24(4):379-84.

\section{KEY TERMS}

Collaboration, Higher Education, Interprofessional Education, Interprofessional Learning, Attitudes, RIPLS 